\title{
Effectiveness of tonic and burst motor cortex stimulation in chronic neuropathic pain
}

This article was published in the following Dove Press journal:

Journal of Pain Research

\author{
Paweł Sokal' \\ Marek Harat ${ }^{2}$ \\ Agnieszka Malukiewicz' \\ Michał Kiec ${ }^{3}$ \\ Milena Świtońska' \\ Renata Jabłońska' \\ 'Department of Neurosurgery and \\ Neurology, Jan Biziel University Hospital \\ nr 2, Ludwik Rydygier Collegium \\ Medicum, Nicolaus Copernicus \\ University, Bydgoszcz, Poland; ${ }^{2}$ Division \\ of Preventive Medicine and Healthy \\ Policy, Ludwik Rydygier Collegium \\ Medicum, Nicolaus Copernicus \\ University, Bydgoszcz, Poland; \\ ${ }^{3}$ Department of Neurosurgery, The I0th \\ Military Clinical Hospital, Bydgoszcz, \\ Poland
}

Background: Motor cortex stimulation (MCS) is an intracranial, invasive method for treatment of chronic pain. Main indications for MCS are central post stroke pain, neuropathic facial pain, phantom limb pain and brachial plexus or spinal cord injury pain. Spinal cord stimulation (SCS) with burst waveform has been proved to be more effective than tonic mode in chronic pain. Necessity to replace depleted batteries of motor cortex tonic stimulators gave us an opportunity of applying burst stimulation. The objective of the pilot study was to evaluate the effects of burst stimulation applied on motor cortex in patients with chronic pain syndromes as well as comparison to tonic mode.

Materials and methods: We have evaluated 6 patients (females $\mathrm{N}=3$, males $\mathrm{N}=3$ ) belonging to the group of 14 cases (females $\mathrm{N}=5$, males $\mathrm{N}=9$ ) who had undergone surgical procedure of MCS in years 2005-2017. Selected for the study were 6 patients with thalamic pain $\mathrm{N}=3$, with facial pain $\mathrm{N}=3$ (anaesthesia dolorosa and neuropathic trigeminal neuralgia). The patients were subjected to both modes of stimulation then they chose which one was better in relieving pain: tonic or burst. Pain intensity was assessed with the visual analogue scale (VAS) before the replacement of implanted pulse generator (IPG) and after the stimulation with tonic and burst modes.

Results: In the study, 5 out of 6 patients with MCS found burst mode more effective than tonic mode. Baseline VAS score in patients that had at least 3 months depleted battery of tonic IPG was $95 \mathrm{~mm}$. After implantation of a new IPG mean VAS score on tonic stimulation was $72 \mathrm{~mm}$, on burst $53 \mathrm{~mm}$.

Conclusions: The most preferred option of MCS in selected group of patients was burst stimulation. This study has shown, that the burst stimulation of cerebral cortex is a promising modality when tonic stimulation is not sufficient in refractory, neuropathic pain.

Keywords: motor cortex stimulation, burst stimulation, neuropathic pain

\section{Introduction}

Motor cortex stimulation (MCS) and deep brain stimulation (DBS) are established intracranial methods for treatment of chronic, neuropathic pain. Main indications for MCS are central post stroke pain, neuropathic facial pain, phantom limb pain, brachial plexus injury pain or spinal cord injury pain. ${ }^{1-7}$ In our previous study good response on tonic MCS in chronic neuropathic pain has been observed in over $50 \%$ with postoperative follow-up of 1 year. ${ }^{8}$ These findings were consistent with the results of other reports. ${ }^{9-11}$ Cortical stimulation has also been used in such conditions as Parkinson's disease and tinnitus. ${ }^{12,13}$ Mechanisms underlying the analgesic effect of MCS has not yet been elucidated, but may be due to stimulation of corticosubcortical fibers, which inhibits hyperactive sensory units in the thalamus. MCS
Correspondence: Paweł Sokal

Department of Neurosurgery and

Neurology, Jan Biziel University Hospital

nr 2, Ludwik Rydygier Collegium

Medicum, Nicolaus Copernicus

University, Ujejskiego 75, Bydgoszcz 85-

168, Poland

Tel +4852365 5505

Email pawel.sokal@cm.umk.pl 
hypothetically modulates thalamic nuclei, cortical somatosensory areas, striatum, cerebellum and inhibits spinothalamic tracts. ${ }^{2,14-16}$ MCS can also control intracortical horizontal fibers instead of direct stimulation of the pyramidal tract. ${ }^{17}$ Tonic stimulation with low frequency in MCS has been applied for years. ${ }^{1,4,8-10,18}$ A new generation of stimulators with the burst waveform are available in spinal cord stimulation (SCS). ${ }^{19-21}$ Necessity of replacement of depleted batteries, which used to provide tonic mode only, gave us an opportunity to use these new generation of cortical stimulators applying other modes including burst stimulation. The burst firing is able to overdrive ongoing tonic firing. ${ }^{22}$ Burst auditory cortex stimulation has been applied in tinnitus patients with better effect on noise-like tinnitus than with tonic stimulation. ${ }^{23}$ In the literature there is one case report on the effects of burst MCS in chronic pain. ${ }^{24}$ SCS with burst waveform has been more effective than tonic in neuropathic pain. ${ }^{25}$ The main feature of commonly used tonic stimulation was low frequency not exceeding $100 \mathrm{~Hz} .^{26,27}$ Frequency and pulse can influence the number of recruited neurons. The burst stimulation in contrast to tonic SCS correlates with the amount of neurons and different neurotransmitter mechanisms of action. ${ }^{25}$ The pattern of SCS burst stimulation is such that $500 \mathrm{~Hz}$ stimulation is delivered in groups of five pulses with 1-ms pulse width and it is repeated 40 times per second in stimulators of spinal cord. ${ }^{25}$ The objective of the pilot study was to evaluate the effects of burst stimulation applied on motor cortex in patients with central neurogenic pain as well as comparison to tonic stimulation.

\section{Materials and methods}

We evaluated 6 patients (females $\mathrm{N}=3$, males $\mathrm{N}=3$ ) belonging to the group of 14 cases (females $\mathrm{N}=5$, males $\mathrm{N}=9$ ) who had undergone surgical procedure of MCS in our institution in years 2005-2017 Table 1.

Approval was obtained from the Ethics Committee at the Military Medical Chamber in Warsaw, Poland (138/16) in accordance with the Declaration of Helsinki. Written informed consent was obtained from each patient. Replacement of a new, implantable pulse generator (IPG) was performed under local anaesthesia with sedation, unlike surgeries of implantation of cranial electrodes and primary IPGs. They had been conducted under general anaesthesia without myorelaxation with the use of MRI based neuronavigation. Craniotomy over the dura covering the motor strip had been performed, motor evoked potentials had been used to confirm proper localization and then four paddle type 4contact electrodes were placed perpendicular to precentral gyrus Figures 1 and 2 or one 16-contact electrode along this gyrus Figure $3 .^{8}$

Half of the selected subjects for the study were patients with thalamic pain $\mathrm{N}=3$, and other half with atypical facial pain $\mathrm{N}=3$ (anaesthesia dolorosa and neuropathic trigeminal neuralgia). Unfortunately all of them had to wait on replacement of IPG for at least 3 months on a waiting list and meanwhile they were complaining about pain exacerbation. These patients received stimulators capable of inducing both tonic or burst stimulation and were given an opportunity to choose the most efficient program of neuromodulation using their own patients' programmer. Patients could change program after 5-7 days of stimulation between tonic and burst. Outcome was based after at least 4 weeks during a control visit basing on personal choice of patients who were selecting the most frequently applied program causing the most efficient pain relief. Pain intensity was assessed with the visual analogue scale (VAS) after the stimulation with both tonic and burst mode. VAS is a continuous line scale, which begins with 0 , no pain and ends with $100 \mathrm{~mm}$ describing as pain "as bad as it could be". ${ }^{28}$ Baseline VAS score was defined as score attained before surgical replacement of IPG when there was no effective stimulation due to depleted battery of tonic stimulator.

\section{Results}

In the study 5 out of 6 patients found burst mode of motor cortex stimulation more effective than tonic. Baseline VAS score without stimulation due to depletion of battery in patients who had been treated previously with tonic MCS was $95 \mathrm{~mm}$. Mean VAS score after tonic stimulation was $72 \mathrm{~mm}$ and improvement after burst stimulation was 53 $\mathrm{mm}$ on average Figure 4. Intensity of pain after subsequent periods of tonic and burst stimulation is presented in Table 2.

\section{Discussion}

MCS is supposed to be last resort of treatment for chronic, neuropathic pain of central and peripheral origin; pain that is refractory to pharmacological treatment and that cannot be treated with other stimulation techniques such as SCS and peripheral nerve stimulation. Frequently after longterm MCS the analgesic effects of neuromodulation are diminished due to habituation on stimulation. ${ }^{8}$ In our series we examined patients with central neurogenic, ie thalamic syndrome after stroke or traumatic brain injury, and 
Table I Characteristics of patients.

\begin{tabular}{|c|c|c|c|c|c|c|c|}
\hline $\mathbf{N}$ & Initials & Sex & Diagnosis & Location & $\begin{array}{l}\text { Pain } \\
\text { period } \\
\text { in years }\end{array}$ & $\begin{array}{l}\text { Tonic MCS } \\
\text { period in } \\
\text { years }\end{array}$ & $\begin{array}{l}\text { Pharmaco- } \\
\text { therapy } \\
\text { reduction }\end{array}$ \\
\hline 1 & $\begin{array}{l}\text { Patient } \\
\text { I }\end{array}$ & $M / 62$ & Thalamic syndrome & LUE left & 13 & 7 & Tramadol \\
\hline 2 & $\begin{array}{l}\text { Patient } \\
2\end{array}$ & $\mathrm{~F} / 48$ & Anesthesia dolorosa & V2 V3 left & 7 & 2 & $\begin{array}{l}\text { Tramadol, } \\
\text { gabapentin }\end{array}$ \\
\hline 3 & $\begin{array}{l}\text { Patient } \\
3\end{array}$ & $\mathrm{~F} / 70$ & Atypical facial pain & $\begin{array}{l}\text { VI V2 V3 } \\
\text { right }\end{array}$ & 16 & 10 & Tramadol \\
\hline 4 & $\begin{array}{l}\text { Patient } \\
4\end{array}$ & $M / 57$ & Thalamic syndrome & LUE right & 16 & 5 & Tramadol \\
\hline 5 & $\begin{array}{l}\text { Patient } \\
5\end{array}$ & $M / 64$ & Thalamic syndrome & LUE left & 13 & 8 & Tramadol \\
\hline 6 & $\begin{array}{l}\text { Patient } \\
6\end{array}$ & $\mathrm{~F} / 62$ & $\begin{array}{l}\text { Neuropathic neuralgia after schwan- } \\
\text { noma surgery }\end{array}$ & V2 V3 left & 11 & 3 & None \\
\hline \multicolumn{5}{|c|}{ Mean values } & 12.7 & 5.8 & \\
\hline
\end{tabular}

Abbreviations: Distribution of pain: LUE, lower and upper extremity; MCS, motor cortex stimulation; VI, first branch of trigeminal nerve; V2, second branch of trigeminal nerve; $\mathrm{V} 3$, third branch of trigeminal nerve.

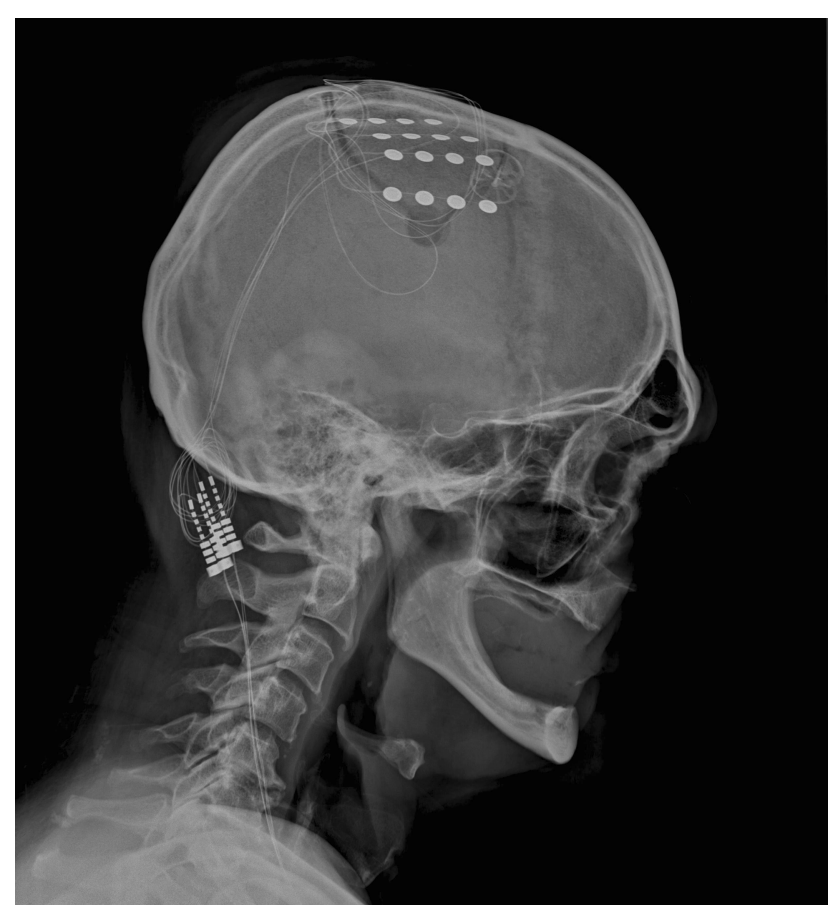

Figure I Four-paddle type electrodes placed on motor cortex in a patient I with thalamic pain predominantly in left upper extremity. 62 years old male with thalamic pain and MCS for 4 years had VAS $=90 \mathrm{~mm}$ on tonic and VAS $=70 \mathrm{~mm}$ on burst mode. Abbreviations: MCS, motor cortex stimulation; VAS, visual analogue scale.

neuropathic facial pain. Out of 14 patients who received MCS, 6 were subjected to burst stimulation of the cerebral cortex. Patients with refractory pain lasting for a long period approximately 16 years (mean value) treated with tonic MCS for approximately 6 years (mean value) posed a challenge for achieving a satisfactory pain reduction.

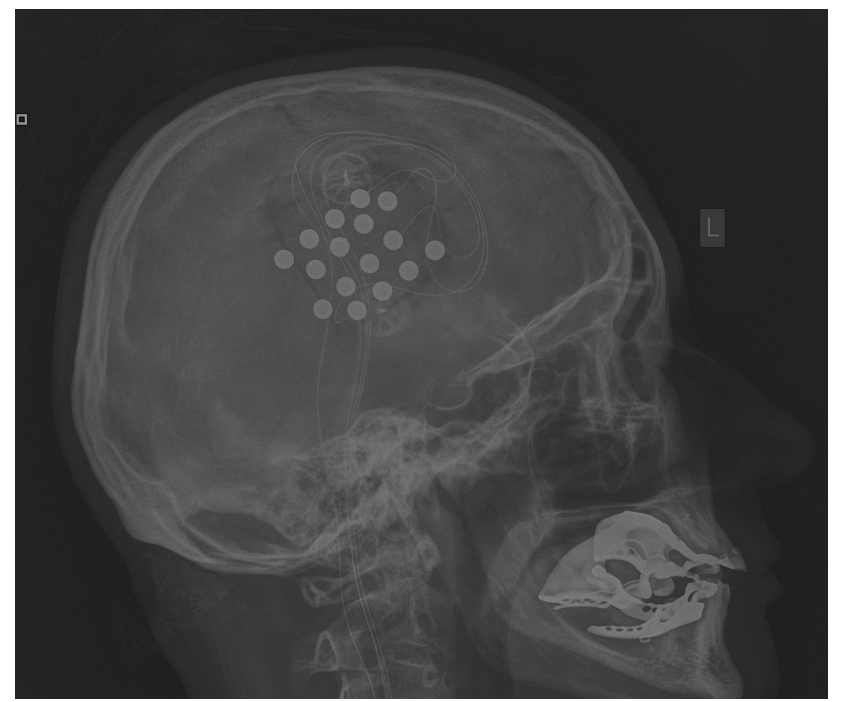

Figure 2 Electrodes placed on motor cortex in a patient 3. 60 years old female with atypical facial pain and with tonic MCS for 10 years had VAS $=70 \mathrm{~mm}$ on five tonic programs and VAS $=40 \mathrm{~mm}$ on burst mode.

Abbreviations: MCS, motor cortex stimulation; VAS, visual analogue scale.

Primary waveform of MCS was tonic stimulation with frequency of $10-50 \mathrm{~Hz}$ with amplitudes from $1-10 \mathrm{~mA}$. Although tonic MCS in the majority of patients with all types of central pain after long-term of stimulation had provided moderate effects, patients demanded reimplantation of IPG, when the battery had been depleted. After the implantation of the new IPG, patients were able to choose between tonic and burst stimulations. The most preferred option was burst stimulation. Due to exacerbation of pain in the period before replacement, patients were receiving 


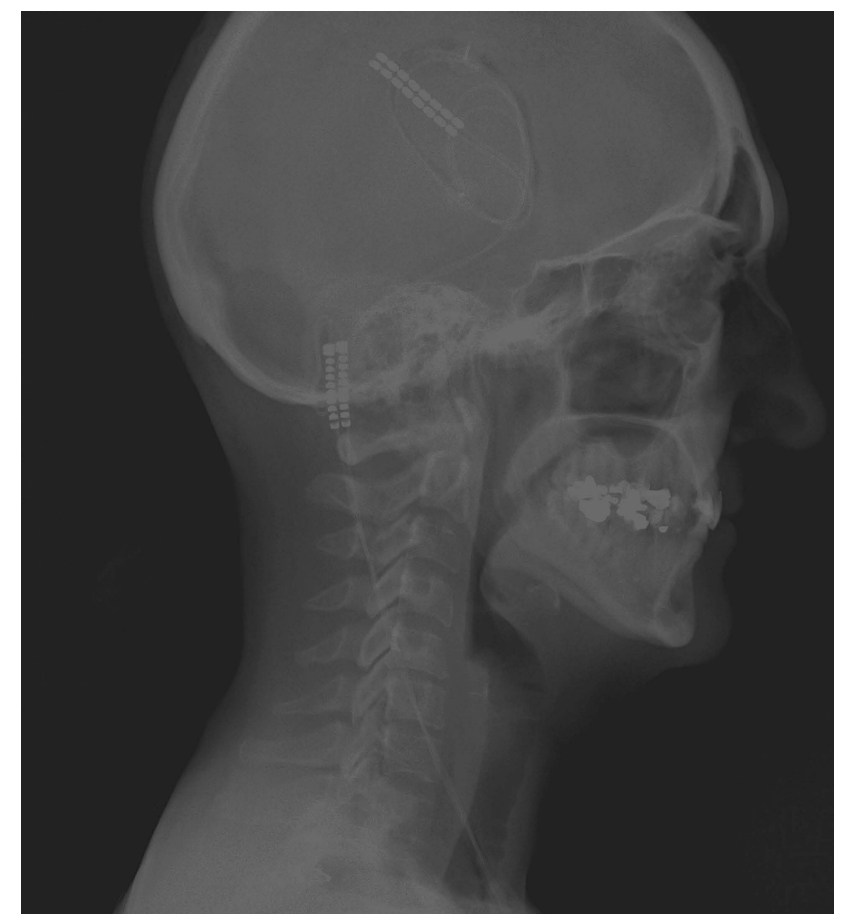

Figure 3 Electrode $2 \times 8$ contact placed on dura along motor strip in patient 2, 48 year old female with anaesthesia dolorosa on face with MCS for 2 years; VAS $=70 \mathrm{~mm}$ on tonic and 50 on burst mode.

Abbreviations: MCS, motor cortex stimulation; VAS, visual analogue scale. analgesics such as tramadol. After surgery they were asked to reduce doses or withdraw it. The majority of them were taking 1 or 2 tramadol daily but no one noticed significant improvement after it. Gabapentin was the medicine administered permanently in unchanged doses to patient 2 before and during both tonic and burst stimulation.

The efficacy of MCS is dependent on proper selection of patients, accurate localization of electrodes and optimal adjusting of parameters. ${ }^{1,3,4,7}$ Suitable location of electrodes nearby central sulcus provide more expressed analgesia than over precentral gyrus. ${ }^{29}$ In tonic MCS - efficacy of pain treatment can be attained by titration of amplitude of current intensity, diversification of contacts or cyclization. ${ }^{30}$ Cycling stimulation was initially recommended by Nguyien, recent Vancouver group presented programming algorithm in which cyclization 15 minutes on and 15 minutes off was the most preferred setting. ${ }^{4,31,32}$ According to Fontaine et al chronic stimulation with parameters $40 \mathrm{~Hz}$, PW 210 can, not only reduce the pain, but also improve sensory discrimination. ${ }^{33}$ Thermal sensory restoration induced by MCS have been noticed also after repetitive transcranial magnetic stimulation (rTMS). Thus sensory changes are the result of reorganization

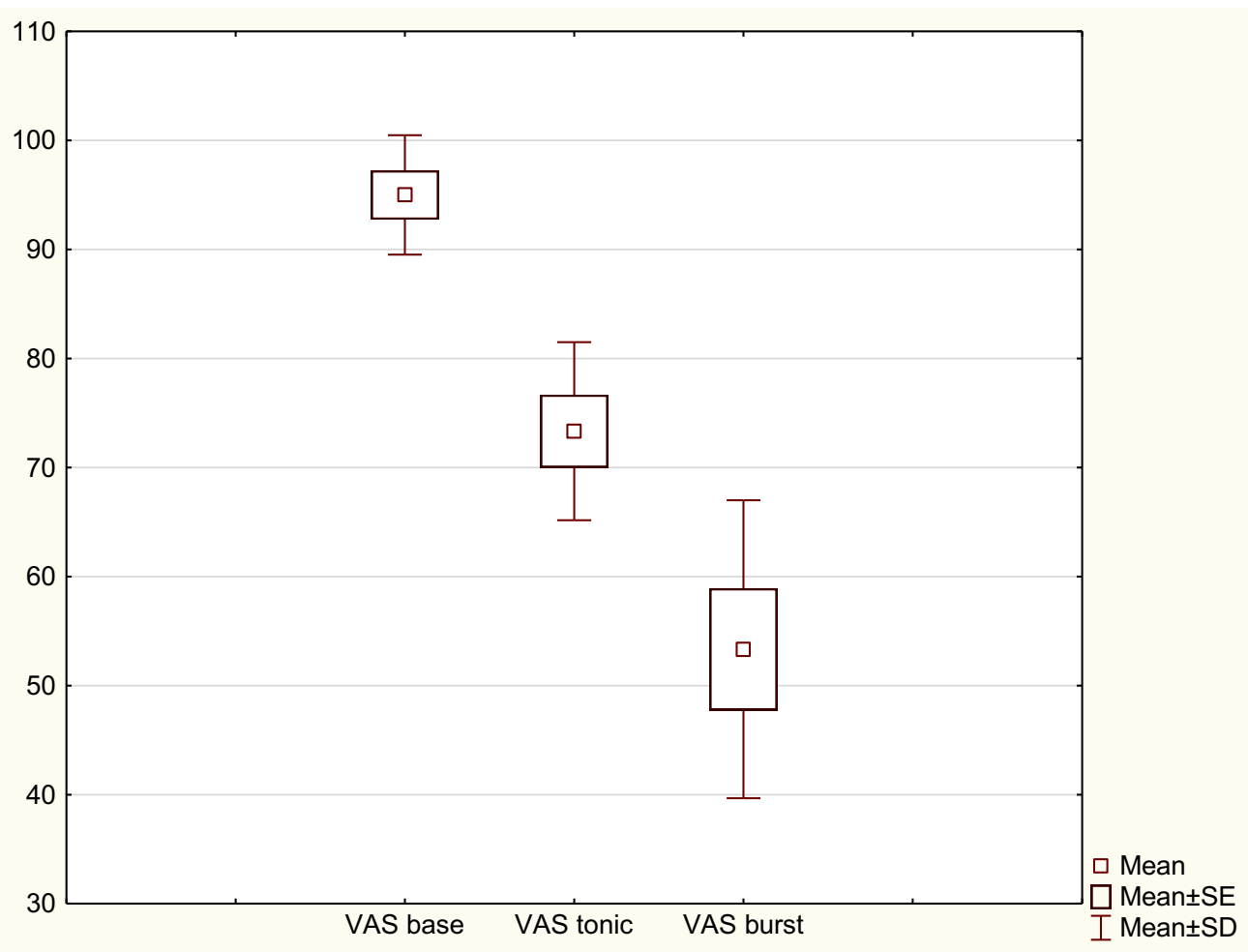

Figure 4 Results of tonic and burst cortical stimulation in VAS score in $\mathrm{mm}$.

Notes: Statistical analysis was performed with software package Statistica Version 10.0. Data were expressed as means \pm SD. Comparisons between groups were performed with analysis of nonparametric repeated measures test ANOVA chi square. $(N=6, d f=2)=1156522 P=0, .00308$. A value of $P<0.05$ was considered statistically significant. Coefficient of concordance $=09638$, average rank $r=095653$. 
Table 2 Level of pain assessed with VAS in mm before application of MCS, on tonic MCS and on burst MCS, with parameters of burst MCS.

\begin{tabular}{|l|l|l|l|l|l|}
\hline $\mathbf{N}$ & Initials & VAS base & VAS tonic & VAS burst & Parameters of burst MCS \\
\hline $\mathrm{I}$ & Patient I & 100 & 90 & 70 & $20 \mathrm{~Hz} / 500 \mathrm{~Hz} / 1000 \mu \mathrm{s} / 2.2 \mathrm{~mA}$ \\
2 & Patient 2 & 90 & 70 & 50 & $40 \mathrm{hz} / 1000 \mu \mathrm{s} / 6.0 \mathrm{~mA}$ \\
3 & Patient 3 & 90 & 70 & 40 & $40 \mathrm{~Hz} / 500 \mathrm{~Hz} / 1000 \mu \mathrm{s} / 0.8 \mathrm{~mA}$ \\
4 & Patient 4 & 100 & 70 & 50 & $40 \mathrm{~Hz} / 500 \mathrm{~Hz} / 1000 \mu \mathrm{s} / 1.0 \mathrm{~mA}$ \\
5 & Patient 5 & 90 & 70 & 40 & $40 \mathrm{~Hz} / 500 \mathrm{~Hz} / 1000 \mu \mathrm{s} / 0.7 \mathrm{~mA}$ \\
6 & Patient 6 & 100 & 70 & 70 & $40 \mathrm{~Hz} / 500 \mathrm{~Hz} / 1000 \mu \mathrm{s} / 3.0 \mathrm{~mA}$ \\
\hline
\end{tabular}

Notes: Patient 2 received IPG Precision Novi (Boston Scientific, Marlborough, USA) and patients I, 3, 4, 5, and 6 received Proclaim IPG (Abbot, Chicago, USA). Patients 3, 4, 5, and 6 had standard burst stimulation with different amplitudes. Patient I had $20 \mathrm{~Hz}$ frequency in burst stimulation. Patient 2 was under burst stimulation modified by Boston Scientific. Abbreviations: VAS, visual analogue scale; MCS, motor cortex stimulation; IPG, implantable pulse generator

of the sensory cortex. Both MCS and rTMS can have influence on neural plasticity of somatosensory cortex. ${ }^{34}$ rTMS have a positive predicitive value on the effects of MCS. ${ }^{35}$ Transcranial magnetic stimulation with paradigm of theta burst stimulation can modulate cognitive and neurologic function in chronic neurologic, psychiatric disorders and pain syndromes. ${ }^{36,37}$ TMS with burst mode has been successfully applied in tinnitus. ${ }^{23}$ Initially burst stimulation has been applied on auditory cortex to suppress tinnitus more effectively than tonic stimulation. ${ }^{22,38}$ De Ridder was the first who reported improvement in trigeminal anesthesia dolorosa after somatosensory cortex stimulation with burst mode, but also to the anterior cingulate cortex and dorsolateral, prefrontal cortex. ${ }^{24}$ Finally, burst stimulation has been developed for spinal cord stimulation. ${ }^{39}$ Burst spinal cord stimulation is hypothesized to react, not only on lateral spinoreticular and spinothalamic ascending pathways and descending inhibitory pathway, but also on medial ascending pathway, which is responsible for affective component of pain. Burst stimulation with $500 \mathrm{~Hz}$ spike mode 40 times per second has been designed in a way that mimics burst firing in the thalamus engaged in generation of tinnitus and pain. ${ }^{40,41}$ This phenomenon can explain better improvement after burst stimulation in MCS in our series (mean VAS=72 after tonic and mean VAS $=48$ after burst). While the burst stimulation and high frequency stimulation in SCS are supposed to be paraesthesia-free methods, MCS both with tonic and burst generally do not induce paraesthesias. This phenomenon may confuse patients in assessment of effects of MCS. The confusion might be associated with the lack of perception of active brain stimulation, which is in general devoid of paraesthesia in both waveforms. In patients' opinion one of the greatest advantages of burst mode was the lack of paraesthesia and reduction of pain.

Contemporary neurostimulation systems allow patients to participate actively in the therapeutic process. Based on reports of patients engaged in the study they acknowledged the possibility to change programs by themselves. This kind of a patient-controlled, neuromodulatory analgesia helps them become more independent. The limitation of the study is a small sample of participants, lack of randomization and lack of double-blind control, which can affect the reliability of this report. Nevertheless, this study has shown that some patients may benefit from the burst stimulation, which mimics the function of the central nervous system.

\section{Conclusions}

Reduction of pain after burst MCS has been clinically meaningful in comparison to tonic stimulation in chronic, neuropathic pain. According to results of this study-burst cortex stimulation is a promising modality in refractory pain in patients habituated to tonic stimulation. New generation stimulators enable improved efficiency of MCS. Further studies with larger cohorts are needed to confirm these preliminary results.

\section{Author contributions}

The study was designed by Pawel Sokal and Marek Harat. Pawel Sokal, Marek Harat recruited patients for the study. Pawel Sokal and Michał Kiec conducted the study including surgeries. Data collection was performed by Pawel Sokal, Agnieszka Malukiewicz and Renata Jablonska. Data analysis was performed by Milena Switonska and Renata Jablonska. Manuscript was prepared by Paweł Sokal with substantial intellectual input of Agnieszka Malukiewicz and Milena Switonska. All authors contributed toward data analysis, drafting and revising the paper, gave final approval of the version to be published and agree to be accountable for all aspects of the work. 


\section{Disclosure}

Paweł Sokal reports financial and nonfinancial support from Medtronic, Abbot and Boston Scientific. Marek Harat reports nonfinancial support from Abbot and Boston Scientfic. Agnieszka Malukiewicz reports nonfinancial support from Boston Scientfic. Michał Kiec reports nonfinancial support from Abbot and Medtronic. The authors report no other conflicts of interest in this work.

\section{References}

1. Tsubokawa T, Katayama Y, Yamamoto T, Hirayama T, Koyama S. Chronic motor cortex stimulation in patients with thalamic pain. $J$ Neurosurg. 1993;78(3):393-401. doi:10.3171/jns.1993.78.3.0393

2. Peyron R, Garcia-Larrea L, Petal DM. Electrical stimulation of precentral cortical area in the treatment of central pain: electrophysiological and PET study. Pain. 1995;62(3):275-286. doi:10.1016/0304-3959(94) 00211-V

3. Velasco M, Velasco F, Brito F, et al. Motor cortex stimulation in the treatment of deafferentation pain. I. Localization of the motor cortex. Stereotact Funct Neurosurg. 2002;79:146-167.

4. Nguyen JP, Lefaucher JP, Le Guerinel C, et al. Motor cortex stimulation in the treatment of central and neuropathic pain. Arch Med Res. 2000;31(3):263-265.

5. Levy R, Deer TR, Henderson J. Intracranial neurostimulation for pain control. Pain Physician. 2010;13(2):157-165.

6. Monsalve GA. Motor cortex stimulation for chronic neuropathic facial pain: A review of the literature. Surg Neurol Int. 2012;3 (Suppl 4):S290-S311.

7. Zabek M, Slawek J, Harat M, et al. Stimulation of the brain and spinal cord to treat movement disorders and pain syndromes - theoretical and practical recommendations. Neurol Neurochir Pol. 2006;40(1):1-9.

8. Sokal P, Harat M, Zielinski P, Furtak J, Paczkowski D, Rusinek M. Motor cortex stimulation in patients with chronic central pain. $A d v$ Clin Exp Med. 2015;24(2):289-296.

9. Rasche D, Ruppolt M, Stippich C, Unterberg A, Tronnier VM. Motor cortex stimulation for long-term relief of chronic neuropathic pain: a 10 year experience. Pain. 2006;121(1-2):43-52. doi:10.1016/j. pain.2005.12.006

10. Velasco F, Arguelles C, Carrillo-Ruiz JD, et al. Efficacy of motor cortex stimulation in the treatment of neuropathic pain: a randomized double-blind trial. J Neurosurg. 2008;108(4):698-706. doi:10.3171/ JNS/2008/108/4/0698

11. Henssen DJHA, Kurt E, van Cappellen van Walsum AM, et al. Longterm effect of motor cortex stimulation in patients suffering from chronic neuropathic pain: an observational study. PLoS One. 2018;13 (1):e0191774. doi:10.1371/journal.pone.0191774

12. Arle JE, Apetauerova D, Zani J, et al. Motor cortex stimulation in patients with Parkinson disease: 12-month follow-up in 4 patients. $J$ Neurosurg. 2008;109(1):133-139. doi:10.3171/JNS/2008/109/7/0133

13. De Ridder D, De Mulder G, Verstraeten E, et al. Primary and secondary auditory cortex stimulation for intractable tinnitus. ORL $J$ Otorhinolaryngol Relat Spec. 2006;68:48-54; discussion 54-45. doi:10.1159/000090491

14. DosSantos MF, Ferreira N, Toback RL, Carvalho AC, DaSilva AF. Potential mechanisms supporting the value of motor cortex stimulation to treat chronic pain syndromes. Front Neurosci. 2016;10:18. doi: $10.3389 /$ fnins. 2016.00018

15. Kim J, Ryu SB, Lee SE, et al. Motor cortex stimulation and neuropathic pain: how does motor cortex stimulation affect pain-signaling pathways? J Neurosurg. 2016;124(3):866-876. doi:10.3171/2015.1.JNS14891
16. Garcia-Larrea L, Peyron R. Motor cortex stimulation for neuropathic pain: from phenomenology to mechanisms. Neuroimage. 2007;37 (Suppl):S71-S79. doi:10.1016/j.neuroimage.2007.05.062

17. Nguyen JP, Nizard J, Keravel Y, Lefaucheur JP. Invasive brain stimulation for the treatment of neuropathic pain. Nat Rev Neurol. 2011;7:699-709. doi:10.1038/nrneurol.2011.138

18. Slotty PJ, Chang S, Honey CR. Motor Threshold and MCS for Pain. Neuromodulation. 2015;18(7):566-571. doi:10.1111/ner.12336

19. de Vos CC, Bom MJ, Vanneste S, Lenders MW, de Ridder D. Burst spinal cord stimu- lation evaluated in patients with failed back surgery syndrome and painful diabetic neuropathy. Neuromodulation. 2014;17(2):152-159. doi:10.1111/ner.12116

20. De Ridder D, Vanneste S, Plazier M, Vancamp T. Mimicking the brain: evaluation of St Jude medical's prodigy chronic pain system with burst technology. Expert Rev Med Devices. 2015;12(2):143-150. doi:10.1586/17434440.2015.985652

21. De Ridder D, Perera S, Vanneste S. Are $10 \mathrm{kHz}$ stimulation and burst stimulation fundamentally the same? Neuromodulation. 2017;20:650-653. doi:10.1111/ner.12614

22. De Ridder D, Vanneste S, van der Loo E, et al. Burst stimulation of the auditory cortex: a new form of neurostimulation for noise-like tinnitus suppression. J Neurosurg. 2010;112(6):1289-1294. doi:10.3171/2009.10. JNS09298

23. De Ridder D, Vanneste S, Kovacs S, et al. Transcranial magnetic stimulation and extradural electrodes implanted on secondary auditory cortex for tinnitus suppression. $J$ Neurosurg. 2011;114(4):903911. doi:10.3171/2010.11.JNS10197

24. De Ridder D, Vanneste S, Van Laere K, Menovsky T. Chasing map plasticity in neuropathic pain. World Neurosurg. 2013;80(6):e901e905. doi:10.1016/j.wneu.2012.12.009

25. De Ridder D, Vanneste S. Burst and tonic spinal cord stimulation: different and common brain mechanisms. Neuromodulation. 2016;19 (1):47-59. doi:10.1111/ner.12368

26. Deer TR, Krames E, Mekhail N, et al. New and evolving neurostimulation therapies. Neuromodulation. 2014;17(6):599-615.

27. Bocci T, De Carolis G, Paroli M, et al. Neurophysiological comparison among tonic, high frequency, and burst spinal cord stimulation: novel insights into spinal and brain mechanisms of action. Neuromodulation. 2018;21(5):480-488.

28. Hawker GA, Mian S, Kendzerska T, French M. Measures of adult pain: Visual Analog Scale for Pain (VAS Pain), Numeric Rating Scale for Pain (NRS Pain), McGill Pain Questionnaire (MPQ), Short-Form McGill Pain Questionnaire (SF-MPQ), Chronic Pain Grade Scale (CPGS), Short Form-36 Bodily Pain Scale (SF-36 BPS), and Measure of Intermittent and Constant Osteoarthritis Pain (ICOAP). Arthritis Care Res. 2011;63(Suppl):S240-S252.

29. Hosomi K, Saitoh Y, Kishima H, et al. Electrical stimulation of primary motor cortex within the central sulcus for intractable neuropathic pain. Clin Neurophysiol. 2008;119(5):993-1001.

30. Henderson JM, Boongrid A, Rosenow JM, Lapresto E, Rezai AR. Recovery of pain control by intensive reprogramming after loss of benefit from motor cortex stimulation for neuropathic pain. Stereotact Funct Neurosurg. 2004;82(5-6):207-213.

31. Nguyen JP, Lefaucheur JP, Decq P. Chronic motor cortex stimulation in the treatment of central and neuropathic pain: correlations between clinical, electrophysiological and anatomical data. Pain. 1999;82 (3):245-251.

32. Ivanishvili Z, Poologaindran A, Honey CR. Cyclization of motor cortex stimulation for parameters for motor cortex stimulation. Neuromodulation. 2015;18(7):566-571.

33. Fontaine D, Hamani C, Lozano A. Efficacy and safety of motor cortex stimulation for chronic neuropathic pain: critical review of the literature. J Neurosurg. 2009;110(2):251-256.

34. Droutot X, Nguyen JP, Peschanski M, Lefaucheur JP. The antalgic efficacy of chronic motor cortex stimulation is related to sensory changes in the painful zone. Brain. 2002;125(Pt 7):1660-1664. 
35. Lefaucheur JP, Ménard-Lefaucheur I, Goujon C, Keravel Y, Nguyen JP. Predictive value of rTMS in the identification of responders to epidural motor cortex stimulation therapy for pain. J Pain. 2011;12(10):1102-1111.

36. Lefaucheur JP, André-Obadia N, Antal A, et al. Evidence-based guidelines on the therapeutic use of repetitive transcranial magnetic stimulation (rTMS). Clin Neurophysiol. 2014;125(11):2150-2206.

37. Antal A, Paulus W. Effects of transcranial theta-burst stimulation on acute pain perception. Restor Neurol and Neurosc. 2010;28(4):477-484

38. Rammo R, Ali R, Pabaney A, Seidman M, Schwalb J. Surgical neuromodulation of tinnitus: a review of current therapies and future applications. Neuromodulation. 2018. doi:10.1111/ner.12793
39. De Ridder D, Vanneste S, Plazier M, van der Loo E, Menovsky T. Burst spinal cord stimulation: toward paresthesia-free pain suppression. Neurosurgery. 2010a;66(5):986-990.

40. De Ridder D, Vancamp T, Vanneste S. Fundamentals of burst stimulation of the spinal cord and brain. In: Krames E, Peckham PH, Rezai AR, editors. Neuromodulation Comprehensive Textbook of Principles, Technologies and Therapies. 2nd ed. Elsevier Ltd, London, UK; 2018:147-160.

41. De Ridder D, Lenders MW, De Vos CC, et al. A two center comparative study on tonic versus burst spinal cord stimulation: amount of responders and amount of pain suppression. Clin J Pain. 2014;31(5):433-437.

\section{Publish your work in this journal}

The Journal of Pain Research is an international, peer reviewed, open access, online journal that welcomes laboratory and clinical findings in the fields of pain research and the prevention and management of pain. Original research, reviews, symposium reports, hypothesis formation and commentaries are all considered for publication. The manuscript management system is completely online and includes a very quick and fair peer-review system, which is all easy to use. Visit http:// www.dovepress.com/testimonials.php to read real quotes from published authors. 